\title{
OVERVIEW OF METHODS OF ISOLATION, CULTIVATION AND GENETIC PROFILING ON HUMAN UMBILICAL CORD STEM CELLS
}

\author{
Katarzyna Stefańska ${ }^{1}$, Rafał Sibiak ${ }^{2}$, Claudia Dompe ${ }^{3}$, Lisa Moncrieff ${ }^{3}$, Greg Hutchings ${ }^{3}$, Krzysztof \\ Janowicz ${ }^{3}$, Bartosz Kempisty ${ }^{1,4,5}$
}

\begin{abstract}
Stem cells possess unique properties, such as self-renewal ability or differentiation capacity into more specialized cells, which makes them particularly relevant for regenerative medicine and cellular therapies. Although embryonic stem cells (ESCs) are capable of differentiation into all cell lineages, their utilization is associated with ethical concerns since they are obtained from embryos. Furthermore, ESCs may form teratomas or cause immune rejection in the clinical setting. Therefore, an effort has been made to utilize stem cells derived from adult tissues, especially mesenchymal stem cells (MSCs). A particularly attractive source of MSCs is the human umbilical cord, which is typically discarded after birth and considered a medical waste, therefore the acquisition of the cells is not associated with any health risk for a patient. Moreover, umbilical cord-derived MSCs do not express MHCII, thus they exhibit reduced immunogenicity. MSCs have been isolated from all compartments of umbilical cord, however the Wharton's jelly-derived MSCs (WJ-MSCs) are the most clinically utilizable. There are two techniques of UC-MSCs isolation: the enzymatic and explant procedures. The explant method involves cell outgrowth of tissue pieces placed into plastic culture vessel after mechanical splitting, whereas the enzymatic technique involves minced tissue digestion in an enzymatic solution. In vitro culture conditions of the isolated cells are highly variable among the researchers, however the most commonly performed molecular assays are homogenous and include: RT-qPCR, flow cytometry and immunocytochemistry.
\end{abstract}

Running title: Human umbilical cord stem cells isolation, cultivation and genetic profiling

Keywords: human umbilical cord, umbilical cord stem cells, mesenchymal stem cells, Wharton's jelly

\footnotetext{
${ }^{1}$ Department of Histology and Embryology, Poznan University of Medical Sciences, Poznań, Poland

${ }^{2}$ Division of Reproduction, Department of Obstetrics, Gynecology and Gynecologic Oncology, Poznan University of Medical Sciences, Poznań, Poland

${ }^{3}$ School of Medicine, Medical Sciences and Nutrition, University of Aberdeen, Aberdeen, United Kingdom

${ }^{4}$ Department of Anatomy, Poznan University of Medical Sciences, Poznań, Poland

${ }^{5}$ Department of Obstetrics and Gynecology, University Hospital and Masaryk University, Brno, Czech Republic

* Correspondence: bkempisty@ump.edu.pl

Full list of author information is available at the end of article
} 


\section{Introduction}

Stem cells have been a major focus of regenerative medicine in recent years. Their unique properties, such as self-renewal ability or differentiation capacity into more specialized cells, offer a great promise for cellular therapies. Stem cells have been isolated from both embryonic and adult tissues, however each source has its limitations. Although embryonic stem cells derived from the inner cell mass of blastocysts are pluripotent and have ability to differentiate into all cell lineages, their acquisition and potential utilization generates several issues. Aside from ethical concerns, embryonic stem cells are prone to teratoma formation after transplantation and there is a risk of immune rejection, since they express MHCII [1].

Therefore, an effort has been made to utilize stem cells derived from adult tissues, especially mesenchymal stem cells (MSCs). As stated by the International Society for Cellular Therapy, these cells are plastic-adherent, they have self-renewal ability, and differentiation potential into osteogenic, chondrogenic and adipogenic lineages, they express CD73, CD90, CD105, while lacking expression of CD14, CD34, CD45, [2]. MSCs have been isolated from various sources, such as bone marrow [3], adipose tissue, dental tissues, skin, salivary gland, limb buds, menstrual blood and perinatal tissues [4].

Perinatal tissues, such as the umbilical cord, represent a particularly attractive source of MSCs, since it is typically discarded after birth and considered a medical waste. Therefore, MSCs acquisition from umbilical cord is less expensive and easier than collecting MSCs from bone marrow aspirate, as it does not require painful procedures and it has no health impact on mother and child [5]. Moreover, umbilical cord-derived MSCs do not express MHCII, thus they exhibit reduced immunogenicity [6].

Among the compartments of the umbilical cord the Wharton's jelly is particularly abundant in MSCs, since it's cell level reaches 4700000 MSCs/ $\mathrm{cm}$ [7]. Wharton's jelly derived MSCs (WJ-MSCs) also exhibit higher proliferation rates and maintain their multipotent features for longer periods in vitro than bone marrow-derived MSCs (BM-MSCs) [8]. Moreover, a study conducted by Subramanian et al. revealed that it provides the best source of clinically utilizable MSCs compared to other parts of the umbilical cord [9].

\section{Histological characterization of human umbilical cord}

Human umbilical cord is a structure connecting fetus to the placenta and it develops at $4^{\text {th }}$ to $8^{\text {th }}$ weeks of pregnancy, while the blood circulation within the cord is established by the end of the $5^{\text {th }}$ week. At term, it is $40-60 \mathrm{~cm}$ long and $1-2 \mathrm{~cm}$ wide [10]. Several main regions of the cord can be distinguished, speifically an outer single layer of amniotic epithelium, the subamnion, the intervascular Wharton's jelly and a perivascular region, that surrounds the umbilical vessels (two arteries and one vein) [9].

The umbilical arteries and vein differ in structure from regular vessels of similar diameter. They comprise tunica intima and tunica media but they lack tunica adventitia [11]. The wall of the umbilical cord vein consists of a thick layer of circular, longitudinal and oblique smooth muscle fibers and internal elastic lamina, whereas the arteries are devoid of internal and external elastic lamina [10].

Tunica adventitia is considered to support vasculature and exhibit contractile function, however in the umbilical cord its role is thought to be fulfilled by Wharton's jelly [12]. It also prevents the vessels from kinking and it provides them with insulation and protection $[11,13]$. Wharton's jelly is an embryonic gelatinous connective tissue containing amorphous ground substance and connective tissue cells [14]. The extracellular matrix comprises collagen (predominantly type I), proteoglycans, such as hyaluronic acid and diffusible plasma proteins [11]. MSCs comprised in the Wharton's jelly resemble fibroblasts. However, they also contain myofilaments and express desmin and vimentin, therefore they have been called 'myofibroblasts' [15]. Since the Wharton's jelly has no nervous or vascular elements (except for the three umbilical vessels), it is unique among other connective tissues [11].

\section{Different methods of umbilical cord stem cells isolation}

MSCs have been isolated from all of the umbilical cord compartments described above and the heterogeneity of cell isolation methods and culture conditions is great. MSCs isolation techniques can be divided into enzymatic and explant procedures. The explant method involves cell outgrowth of tissue pieces placed into plastic culture vessel after mechanical splitting. Whereas the enzymatic technique involves minced tissue digestion in an enzymatic solution. After such incubation, the extracellular matrix dissolves and the released cells are seeded into culture dishes in growth medium $[4,16]$.

The MSCs from amniotic epithelium have been isolated by Gonzalez et al. among others, and the procedure involved washing the umbilical cord with HBBS and $10 \%$ betadine solution with HBBS. Afterwards the cords were cut into $\sim 1 \mathrm{~cm}$ cross sections, which were then cut longitudinally to remove the vein, the arteries and the Wharton's jelly. The obtained umbilical cord lining was dissected into smaller pieces, put into HBBS and then seeded onto human fibronectin-coated six well dishes as explants [17].

To retrieve human umbilical vein endothelial cells (HUVECs), the vein must be catheterized and rinsed with PBS in order to remove residual blood. Then the vein is filled with collagenase solution, 
the type of collagenase used (type I or IV), its concentration and incubation times, varies in different investigators [8]. After digestion, the collagenase solution with released cells is collected, washed with PBS, suspended in culture medium and seeded into culture dishes [18]. The perivascular zone of the vessels is also abundant in MSCs and the cells are retrieved with the use of enzymatic procedure as well, a collagenase solution or an enzymatic cocktail composed of dispase, hyaluronidase, collagenase and trypsin are utilized [8,19].

Wharton's jelly is the most common source of umbilical cord-derived MSCs. The study performed by Bharti et al. revealed that regardless of the part of umbilical cord used for WJ-MSCs isolation (the central part or the parts in the proximity of mother or the fetus), Wharton's jelly provides a valuable source of MSCs [20] and their isolation can be conducted both enzymatically and non-enzymatically. Briefly, the umbilical vessels are removed from the cord and the mucous tissue is minced into small fragments, excluding the amniotic epithelium. Then the tissue pieces are then either put in culture plates to attach to the plastic bottom to proceed with the explant method, or they are digested in the enzymatic solution in $37^{\circ} \mathrm{C}$ and the released cells are collected and seeded in culture vessels [8]. Both the incubation time and the types of enzymes used for the digestion vary between researchers, although collagenase is utilized most commonly. However, the use of trypsin and collagenase combined with other enzymes (e.g. hyaluronidase) has been described [21].

\section{In vitro cultivation of umbilical cord - derived cells}

In vitro culture is a critical step required for MSCs to be utilized therapeutically, since the cell number obtained from the tissue is insufficient for clinical application. Umbilical cord-derived stem cells (UCMSCs) are usually cultured at $37^{\circ} \mathrm{C}$ in a humified $5 \%$ $\mathrm{CO}_{2}$ atmosphere. However it has been reported that the atmospheric concentration of the oxygen can be relatively toxic for the cells and the hypoxic conditions could be beneficial for their growth [5,22]. Since UC-MSCs are plastic-adherent, they are cultured either in flasks or plates and the culture medium is most commonly supplemented with $10 \%$ fetal bovine serum (FBS), however the use of $15 \%$ FBS has been described as well $[23,24]$. It is important to note that the addition of FBS has its disadvantages, such as risks of contamination by prions, bacteria and viruses, and the immunological reaction against xenogenic components may occur in the clinical setting [25]. To overcome such limitations, the use of human serum [26], platelet lysate [27] or cord blood serum [28], instead of FBS, has been proposed.

The types of media used for UC-MSCs in vitro culture are highly heterogenous. For the growth of cells derived from the umbilical vein low glucose DMEM
[29], M199 [30] and MEM [18] without exogenous growth factors (that could induce cell differentiation) have been used with a success. Endothelial cells do not spread, migrate or proliferate when cultured in aforementioned media, therefore there is no risk of contamination of MSCs culture [8]. MSCs obtained from the perivascular zone of the umbilical vessels have been cultured in either MEM supplemented with 15\% FBS [24] or low serum culture media, which is composed of low glucose DMEM, 2\% FBS, 40\% MCDB-201 and growth factors such as insulin and dexamethasone in a hypoxic atmosphere [31]. For the growth of MSCs derived from the amniotic epithelium the medium used were DMEM supplemented with 15\% FBS, non-essential amino acids and vitamins [17] or PTTe-1 medium supplemented with 2,5\% FBS and growth factors (insulin-like growth factor-1, PDGF-BB, TGF- $\beta 1$ and insulin) [32].

Since Wharton's jelly is the most popular source of MSCs obtained from the umbilical cord, the variety of WJ-MSCs culture conditions is the highest among other UC-MSCs. The types of media used include DMEM, high or low glucose DMEM, RPMI 1640, MEM, DMEM/F12, HMSCGM, KO-DMEM, with or without growth factors such as bFGF, EGF, insulin, dexamethasone, ascorbic acid, PDGF-BB, and the concentration of supplemented FBS varies from $2 \%$ to $20 \%$, while the use of FCS, human serum or UC blood serum instead of FBS has also been reported (reviewed by Conconi et al. [8]).

\section{Overview of molecular assays on umbilical cord cells - most common examples}

Apart from differentiation assays towards the osteogenic, chondrogenic and adipogenic lineages, several molecular assays were performed on UCMSCs to confirm their stemness and multipotency. One of the most commonly used assays is immunoprofiling of isolated cells to assess their surface antigen phenotype with the use of flow cytometry. Briefly, the cells are stained with FITC- or APC-labeled monoclonal antibodies that are specific for CD14, CD45, CD73, CD90, CD105 and HLA-DR antigens [33]. Additional antibodies against CD34, CD44 may be used as well [34]. Then the cells are analyzed by cytometer and the positive ones are counted, which allows to assess whether the isolated cells fit the ISCT criteria for MSCs.

Moreover, immunocytochemistry may be performed to investigate UC-MSCs surface antigen phenotype as well. The cells are fixed and permeabilized and then incubated with antibodies conjugated with fluorescent stains against human antigens (either the antigens mentioned above, or additional ones) in order to confirm results obtained from the flow cytometry. After that, the stained samples are examined under a fluorescent microscope [35].

In order to investigate the transcriptome of umbilical cord-derived cells, the reverse transcrip- 
tion-quantitative polymerase chain reaction (RT-qPCR) is utilized. To perform RT, RNA is extracted from the cells with the use of TRIzol reagent or commercially available kit and then the complementary DNA (cDNA) is synthesized. After that, the PCR mix with SYBR-green and specific primers is prepared and the reaction is performed using the PCR machine. The most commonly primers used for the reaction include: Nanog, SOX-2, SSEA4, Oct-3/4, which are embryonic stem cells markers (reviewed by [8]).

\section{Conclusions}

Umbilical cord-derived stem cells offer a great promise for regenerative medicine. The cells obtained from all umbilical cord compartments exhibit features characteristic of MSCs. They are plastic-adherent, have self-renewal ability, differentiation potential into osteogenic, chondrogenic and adipogenic lineages, express CD73, CD90, CD105, while lacking expression of CD14, CD34, CD45. The most commonly performed molecular assays are aimed to confirm these cells stemness and multipotency. On the other hand, the isolation and cultivation methods are highly variable among researchers, therefore probably each laboratory should develop its own protocol of obtaining and in vitro culture of UC-MSCs.

\section{Ethical approval}

The conducted research is not related to either human or animal use.

\section{Corresponding author}

Bartosz Kempisty, Department of Anatomy, Poznan University of Medical Sciences, 6 Święcickiego St., 60-781 Poznań, Poland, Tel./ Fax: +48 61 8546565, e-mail: bkempisty@ump.edu.pl.

\section{Conflict of interest statement}

The authors declare they have no conflict of interest.

\section{References}

1. Doğan A. Embryonic Stem Cells in Development and Regenerative Medicine, Springer, Cham; 2018, p. 1-15; DOI:10.1007/5584_2018_175.

2. Dominici M, Le Blanc K, Mueller I, Slaper-Cortenbach I, Marini F., Krause DS, Deans RJ, Keating A, Prockop DJ, Horwitz EM. Minimal criteria for defining multipotent mesenchymal stromal cells. The International Society for Cellular Therapy position statement. Cytotherapy. 2006;8:3157; DOI:10.1080/14653240600855905.

3. Friedenstein AJ, Chailakhjan RK, Lalykina KS. THE DEVELOPMENT OF FIBROBLAST COLONIES IN MONOLAYER CULTURES OF GUINEA-PIG BONE MARROW AND SPLEEN CELLS. Cell Prolif. 1970;3:393-403; DOI:10.1111/j.1365-2184.1970.tb00347.x.

4. Mushahary D, Spittler A, Kasper C, Weber V, Charwat V. Isolation, cultivation, and characterization of human mesenchymal stem cells. Cytom Part A. 2018;93:19-31; DOI:10.1002/cyto.a.23242.

5. Weiss ML, Troyer DL. Stem cells in the umbilical cord. Stem Cell Rev. 2006;2:155-62; DOI:10.1007/s12015-006-0022-y.

6. Cho PS, Messina DJ, Hirsh EL, Chi N, Goldman SN, Lo DP, Harris IR, Popma SH, Sachs DH, Huang CA. Immunogenicity of umbilical cord tissue-derived cells. Blood. 2008;111:430-8; DOI:10.1182/ blood-2007-03-078774.

7. Vangsness CT, Sternberg H, Harris L. Umbilical Cord Tissue Offers the Greatest Number of Harvestable Mesenchymal Stem Cells for Research and Clinical Application: A Literature Review of Different Harvest Sites. Arthrosc J Arthrosc Relat Surg. 2015;31:1836-43; DOI:10.1016/j. arthro.2015.03.014

8. Conconi MT, Liddo R Di, Tommasini M, Calore C, Parnigotto PP. Phenotype and Differentiation Potential of Stromal Populations Obtained from Various Zones of Human Umbilical Cord: An Overview. Open Tissue Eng Regen Med J. 2011; DOI:10.2174/1875043501104010006.
9. Subramanian A, Fong C-Y, Biswas A, Bongso A. Comparative Characterization of Cells from the Various Compartments of the Human Umbilical Cord Shows that the Wharton's Jelly Compartment Provides the Best Source of Clinically Utilizable Mesenchymal Stem Cells. PLoS One. 2015;10; DOI:10.1371/JOURNAL.PONE.0127992.

10. Spurway J, Logan P, Pak S. The development, structure and blood flow within the umbilical cord with particular reference to the venous system. Australas J Ultrasound Med. 2012;15:97-102; DOI:10.1002/j.2205-0140.2012.tb00013.x

11. Davies JE, Walker JT, Keating A. Concise Review: Wharton's Jelly: The Rich, but Enigmatic, Source of Mesenchymal Stromal Cells. Stem Cells Transl Med. 2017;6:1620-30; DOI:10.1002/sctm.16-0492.

12. Lyons FG, Mattei TA. Sources, Identification, and Clinical Implications of Heterogeneity in Human Umbilical Cord Stem Cells, Springer, Cham: 2019, p. 243-56; DOI:10.1007/978-3-030-24108-7_13.

13. Watson N, Divers R, Kedar R, Mehindru A, Mehindru A, Borlongan MC, Borlongan C V. Discarded Wharton's Jelly of the Human Umbilical Cord A Viable Source for Mesenchymal Stem Cells. Cytotherapy. 2015;17:18; DOI:10.1016/J.JCYT.2014.08.009.

14. Nanaev AK, Kohnen G, Milovanov AP, Domogatsky SP, Kaufmann P. Stromal differentiation and architecture of the human umbilical cord. Placenta. 1997;18:53-64; DOI:10.1016/S0143-4004(97)90071-0.

15. Takechi K, Kuwabara Y, Mizuno M. Ultrastructural and immunohistochemical studies of Wharton's jelly umbilical cord cells. Placenta. 1993;14:235-45; DOI:10.1016/S0143-4004(05)80264-4.

16. Nagamura-Inoue T, He H. Umbilical cord-derived mesenchymal stem cells: Their advantages and potential clinical utility. World J Stem Cells. 2014;6:195-202; DOI:10.4252/wjsc.v6.i2.195.

17. Gonzalez R, Griparic L, Umana M, Burgee K, Vargas V, Nasrallah R, Silva F Patel A. An Efficient Approach to Isolation and Characterization of Preand Postnatal Umbilical Cord Lining Stem Cells for Clinical Applications. Cell Transplant. 2010;19:1439-49; DOI:10.3727/096368910X514260.

18. Covas DT, Siufi JLC, Silva ARL, Orellana MD. Isolation and culture of umbilical vein mesenchymal stem cells. Brazilian J Med Biol Res. 2003;36:1179-83; DOI:10.1590/S0100-879X2003000900006.

19. Gökçinar-Yagci B, Özyüncü Ö, Çelebi-Saltik B. Isolation, characterisation and comparative analysis of human umbilical cord vein perivascular cells and cord blood mesenchymal stem cells. Cell Tissue Bank. 2016;17:345-52; DOI:10.1007/s10561-015-9542-5.

20. Bharti D, Shivakumar SB, Park J-K, Ullah I, Subbarao RB, Park J-S, Lee S-L, Park B-W, Rho G-J. Comparative analysis of human Wharton's jelly mesenchymal stem cells derived from different parts of the same umbilical cord. Cell Tissue Res. 2018;372:51-65; DOI:10.1007/ s00441-017-2699-4.

21. Salehinejad P, Alitheen NB, Ali AM, Omar AR, Mohit M, Janzamin E, Samani FS, Torshizi Z, Nematollahi-Mahani SN. Comparison of different methods for the isolation of mesenchymal stem cells from human umbilical cord Wharton's jelly. Vitr Cell Dev Biol - Anim. 2012;48:75-83; DOI:10.1007/s11626-011-9480-x.

22. Hoffmann A, Floerkemeier T, Melzer C, Hass R. Comparison of in vitro -cultivation of human mesenchymal stroma/stem cells derived from bone marrow and umbilical cord. J Tissue Eng Regen Med. 2017;11:2565-81; DOI:10.1002/term.2153.

23. Ranjbaran H, Abediankenari S, Mohammadi M, Jafari N, Khalilian A, Rahmani Z, Momeninezhad Amiri M, Ebrahimi P. Wharton's Jelly Derived-Mesenchymal Stem Cells: Isolation and Characterization. Acta Med Iran. 2018;56:28-33.

24. Sarugaser R, Lickorish D, Baksh D, Hosseini MM, Davies JE. Human Umbilical Cord Perivascular (HUCPV) Cells: A Source of Mesenchymal Progenitors. Stem Cells. 2005;23:220-9; DOI:10.1634/stemcells.2004-0166.

25. Hassan G, Kasem I, Soukkarieh C, Aljamali M. A Simple Method to Isolate and Expand Human Umbilical Cord Derived Mesenchymal Stem Cells: Using Explant Method and Umbilical Cord Blood Serum. Int J Stem Cells. 2017;10:184-92; DOI:10.15283/ijsc17028.

26. Tateishi K, Ando W, Higuchi C, Hart DA, Hashimoto J, Nakata K, Yoshikawa H, Nakamura N. Comparison of Human Serum with Fetal Bovine Serum for Expansion and Differentiation of Human Synovial MSC: Potential Feasibility for Clinical Applications. Cell Transplant. 2008;17:549-57; DOI:10.3727/096368908785096024.

27. Bieback K. Platelet Lysate as Replacement for Fetal Bovine Serum in Mesenchymal Stromal Cell Cultures. Transfus Med Hemotherapy. 2013;40:326-35; DOI:10.1159/000354061.

28. SHETTY P, BHARUCHA K, TANAVDE V. Human umbilical cord blood serum can replace fetal bovine serum in the culture of mesenchymal stem cells. Cell Biol Int. 2007;31:293-8; DOI:10.1016/j.cellbi.2006.11.010.

29. Secco M, Zucconi E, Vieira NM, Fogaça LLQ, Cerqueira A, Carvalho MDF Jazedje T, Okamoto OK, Muotri AR, Zatz M. Multipotent Stem Cells from Umbilical Cord: Cord Is Richer than Blood! Stem Cells. 2008;26:146-50; DOI:10.1634/stemcells.2007-0381. 
30. Panepucci RA, Siufi JLC, Silva WA, Proto-Siquiera R, Neder L, Orellana M, Rocha V, Covas DT, Zago MA. Comparison of Gene Expression of Umbilical Cord Vein and Bone Marrow-Derived Mesenchymal Stem Cells. Stem Cells. 2004;22:1263-78; DOI:10.1634/stemcells.2004-0024.

31. Farias VA, Linares-Fernández JL, Peñalver JL, Payá Colmenero JA, Ferrón GO, Duran EL, Fernández RM, Olivares EG, O’Valle F, Puertas A, Oliver FI Ruiz de Almodóvar JM. Human umbilical cord stromal stem cell express CD10 and exert contractile properties. Placenta. 2011;32:86-95; DOI:10.1016/j.placenta.2010.11.003.

32. Reza HM, Ng B-Y, Phan TT, Tan DTH, Beuerman RW, Ang LP-K. Characterization of a Novel Umbilical Cord Lining Cell with CD227 Positivity and Unique Pattern of P63 Expression and Function. Stem Cell Rev Reports. 2011;7:624-38; DOI:10.1007/s12015-010-9214-6.

33. Beeravolu N, McKee C, Alamri A, Mikhael S, Brown C, Perez-Cruet M Chaudhry GR. Isolation and Characterization of Mesenchymal Stromal Cells from Human Umbilical Cord and Fetal Placenta. J Vis Exp. 2017; DOI:10.3791/55224.

34. Zhuang Y, Li D, Fu J, Shi Q, Lu Y, Ju X. Comparison of biological properties of umbilical cord-derived mesenchymal stem cells from early and late passages: immunomodulatory ability is enhanced in aged cells. Mol Med Rep. 2015;11:166-74; DOI:10.3892/mmr.2014.2755.

35. Peng J, Wang Y, Zhang L, Zhao B, Zhao Z, Chen J, Guo Q, Liu S, Sui X, Xu W, Lu S. Human umbilical cord Wharton's jelly-derived mesenchymal stem cells differentiate into a Schwann-cell phenotype and promote neurite outgrowth in vitro. Brain Res Bull. 2011;84:235-43; DOI:10.1016/j. brainresbull.2010.12.013. 